\title{
Dynamics of Urine Microbial Landscape in Children with Urinary Tract Infections Treated in Multi-Discipline Hospitals
}

DOI: $10.17691 / \mathrm{stm} 2019.11 .2 .17$

Received April 4, 2018

A.N. Obukhova, MD, Clinical Resident, Department of Hospital Pediatrics ${ }^{1}$;

E.V. Tush, MD, PhD, Associate Professor, Department of Hospital Pediatrics ${ }^{1}$;

D.A. Kireev, MD, Urologist, $2^{\text {nd }}$ Urology Department ${ }^{2}$;

T.V. Nosova, MD, Bacteriologist ${ }^{3}$;

L.A. Bakunova, MD, Pediatrician;

I.F. Voevodkina, MD, Pediatrician";

N.B. Kireeva, MD, DSc, Professor, Department of Pediatric Surgery ${ }^{1}$;

O.V. Khaletskaya, MD, DSc, Professor, Head of the Department of Hospital Pediatrics ${ }^{1}$

${ }_{1}^{1}$ Privolzhsky Research Medical University, 10/1 Minin and Pozharsky Square, Nizhny Novgorod, 603005, Russia;

${ }^{2}$ Nizhny Novgorod Regional Clinical Hospital named after N.A. Semashko, 190 Rodionova St., Nizhny Novgorod, 603126, Russia;

${ }^{3}$ Children's City Clinical Hospital No.1, 76 Prospect Gagarina, Nizhny Novgorod, 603081, Russia

The aim of the study was to characterize the microbial landscape in the urine of children treated in multi-discipline hospitals based on the spectrum and drug-resistance of the urinary tract bacteria.

Materials and Methods. The bacterial strains isolated from the urine of patients aged 1 month to 18 years with urinary tract infections treated in the pediatric wards of Nizhny Novgorod clinics from 2005 to 2017 were studied. The degree of bacteriuria and sensitivity to antibiotics/antibacterial agents were determined.

Results. The results indicated a change in the spectrum of pathogens in urine samples of patients that underwent treatment in the Children's City Clinical Hospital No.1 (Nizhny Novgorod) during 2000-2016. A mixture of microbial species that prevailed earlier has been replaced with bacteria monocultures in recent years (2014-2016). Among those, gram-negative bacteria dominated (E. coli, Klebsiella, Proteus); the gram-positive flora was represented by the Streptococcus, Enterococcus, and Staphylococcus genera. Since 2014, the occurrence rate of Klebsiella has increased to $14.7 \%$.

In the surgery department of the Regional Children's Clinical Hospital of Nizhny Novgorod, gram-negative bacteria monocultures dominated throughout the entire study period (2005-2017). Among the gram-positive flora, bacteria of the Staphylococcus genus took the lead. In recent years, the occurrence of Klebsiella has also increased.

Conclusion. Over the past 16 years, a change in the spectrum of the urinary tract pathogens occurred in both pediatric and surgery departments of multi-discipline children's hospitals. Continuous monitoring of urinary microflora and its sensitivity to antibiotics and other antimicrobial drugs is important for adjusting urinary tract infections therapy in pediatric patients.

Key words: urinary tract infections in children; bacterial flora; antimicrobial therapy; monitoring of pathogens.

\section{Introduction}

Resistance of pathogenic bacteria to antimicrobial therapy is a significant factor of consideration for the urinary tract infection (UTI) treatment. The term UTI refers to the bacterial growth in the urinary tract, which is characteristic of acute and chronic pyelonephritis, acute and chronic cystitis, vesicoureteral reflux associated with obstructive and non-obstructive pyelonephritis, and some other diseases.

The biological properties of microorganisms colonizing the renal tissue, as well as impaired urodynamics are the major factors contributing to the development of UTIs.
According to the clinical guidelines for the diagnosis and treatment of urinary infections in children, the UTI prevalence is 18 cases per 1000 children population [1, 2]. Among infants and toddlers, UTI is the most common and severe bacterial infection. The occurrence rate of UTI is similar among boys and girls of the first year of life ( $1 \%$ respectively), but at an older age (10 to 15 years), the incidence of UTI-infected girls is 9 times higher than that of boys, due to anatomical and physiological differences and endocrine adjustments due to menarche [3].

A key element in the treatment of UTI is therapy with antibiotics and other antimicrobial drugs. In this strategy, a focus on drug-sensitivity of the pathogenic bacteria is

Corresponding author: Anna N. Obukhova, e-mail: obukhovaanna@mail.ru 
strongly advised. However, the rapid growth of microbial drug-resistance and the emergence of multiresistant strains have become a major obstacle to successful antimicrobial therapy. The changing sensitivity of urine pathogenic bacteria to antibiotic makes the adequate choice of antibiotic therapy rather difficult. At the same time, the number of new antibiotics approved by the US Food and Drug Administration (FDA) is steadily decreasing $[4,5]$.

The aim of the study was to characterize the microbial landscape in the urine of children treated in multi-discipline hospitals based on the spectrum and drug-resistance of the urinary tract bacteria.

\section{Materials and Methods}

The below retrospective analysis was based on continuous data sampling from the bacteriology test results in children with UTIs treated in the Children's City Clinical Hospital No.1 ( $\mathrm{CCCH})$ and the Regional Children's Clinical Hospital (RCCH) of Nizhny Novgorod. Urine culture + antibiotic sensitivity assays were carried out according to the standard techniques. The urine samples were collected as required by the $\mathrm{MU}$ 4.2.2039-05 document "Technique for collecting and transporting biomaterials in microbiological laboratories" [6]. The morning urine was used for the measurements throughout the entire period of data analysis. Before giving the urine, children performed the indicated hygienic procedures on their genitals. In the pediatric wards, disposable sterile baby bags for infants and sterile cups for older children were used. In the surgical department, the girls' urine was collected using disposable urethral catheters; the boys urinated directly into sterile cups.

Within $2 \mathrm{~h}$, the collected material was delivered to the laboratory under the isothermal conditions. The cultures were grown on the HiCrome UTI Agar medium (HiMedia Laboratories Pvt. Ltd, India). The morphological study of the microorganisms was performed using the Gram procedure. The sensitivity to antibiotics was assessed using the standard disc method. The diagnostically significant bacteriuria was confirmed by the presence of $>10^{5}$ colony-forming units (CFU) of bacteria in $1 \mathrm{ml}$ of mid-stream urine, or the presence of one species of bacteria at $\geq 10^{4} \mathrm{CFU} / \mathrm{ml}$ in the catheter-obtained urine $[7,8]$. The level of drug-resistance of the pathogens was determined by the minimum inhibitory concentration (MIC), i.e. by the lowest concentration of the antibiotic that suppresses the visible growth of the microorganism in vitro. The high level of resistance was diagnosed in the absence of a clinical effect under the maximal therapeutic doses of the antibiotic. The moderate level corresponded to a good clinical efficacy observed under the maximal therapeutic doses of the drug or when the infection was localized in the areas of high concentrations of the antibiotic. The low level of drugresistance was determined by a good therapeutic efficacy under the standard therapeutic doses of the given antimicrobial agent [9].

In the $\mathrm{CCCH}$, we analyzed the results of 865 bacterial cultures made in 2016, 853 — in 2014, 570 - in 2003, and 522 - in 2000. Children who stayed in the hospital in 2014 and 2016 were distributed into two age groups (Table 1). Group 1 included children aged from 1 month to 3 years, group 2 - from 4 to 18 years.

In the surgery department of the $\mathrm{RCCH}$, the results of 254 cultures tested in 2005-2015 and 476 cultures from 2016-2017 were analyzed. The patients were assigned into the similar age groups (see Table 1).

Statistical data processing was performed using Microsoft Excel 2000, BioStat (Primer of Biostatistics 4.03) and the $\chi^{2}$ criterion. The differences were considered significant at $p<0.05$.

\section{Results and Discussion}

According to the records from the pediatric departments of the $\mathrm{CCCH}$, in 2014, bacterial presence was found in urine samples from 392 out of 853 patients $(45.9 \%)$ of both age groups. In $55.4 \%$ of cases $(217 / 392)$, that was represented by monocultures, in $44.6 \%$ (175/392) - by mixed flora. Analysis of the microflora species showed that gram-negative flora dominated $(89.4 \% ; 194 / 217)$ in both age groups. This type of bacteria was represented mainly by $E$. coli $(67.3 \%$; 146/217), Klebsiella (14.7\%; 32/217), and Acinetobacter (3.2\%; 7/217) (Figure 1 (a)). Pseudomonas aeruginosa was detected in the older age group only. This species amounted up to $1.3 \%$ of the total bacterial flora in urine samples from this group (1/84). The Proteus genus was found only in the younger children $(2 \% ; 5 / 133)$. Grampositive flora was represented by the Streptococcus genus $(0.4 \% ; 2 / 133$ - in the younger group; $1.3 \%$;

Table 1

Distribution of the examined children by gender and age

\begin{tabular}{|c|c|c|c|c|c|c|c|c|c|c|c|c|}
\hline \multirow{3}{*}{ Patients } & \multicolumn{6}{|c|}{ Pediatric departments of $\mathrm{CCCH}$} & \multicolumn{6}{|c|}{ Surgery department of RCCH } \\
\hline & \multicolumn{3}{|c|}{2014} & \multicolumn{3}{|c|}{2016} & \multicolumn{3}{|c|}{$2005-2015$} & \multicolumn{3}{|c|}{ 2016-2017 } \\
\hline & Boys & Girls & Total & Boys & Girls & Total & Boys & Girls & Total & Boys & Girls & Total \\
\hline Younger group & 173 & 260 & 433 & 151 & 253 & 404 & 81 & 33 & 114 & 144 & 91 & 235 \\
\hline Older group & 109 & 311 & 420 & 147 & 314 & 461 & 47 & 93 & 140 & 132 & 109 & 241 \\
\hline Total & 282 & 571 & 853 & 298 & 567 & 865 & 128 & 126 & 254 & 276 & 200 & 476 \\
\hline
\end{tabular}




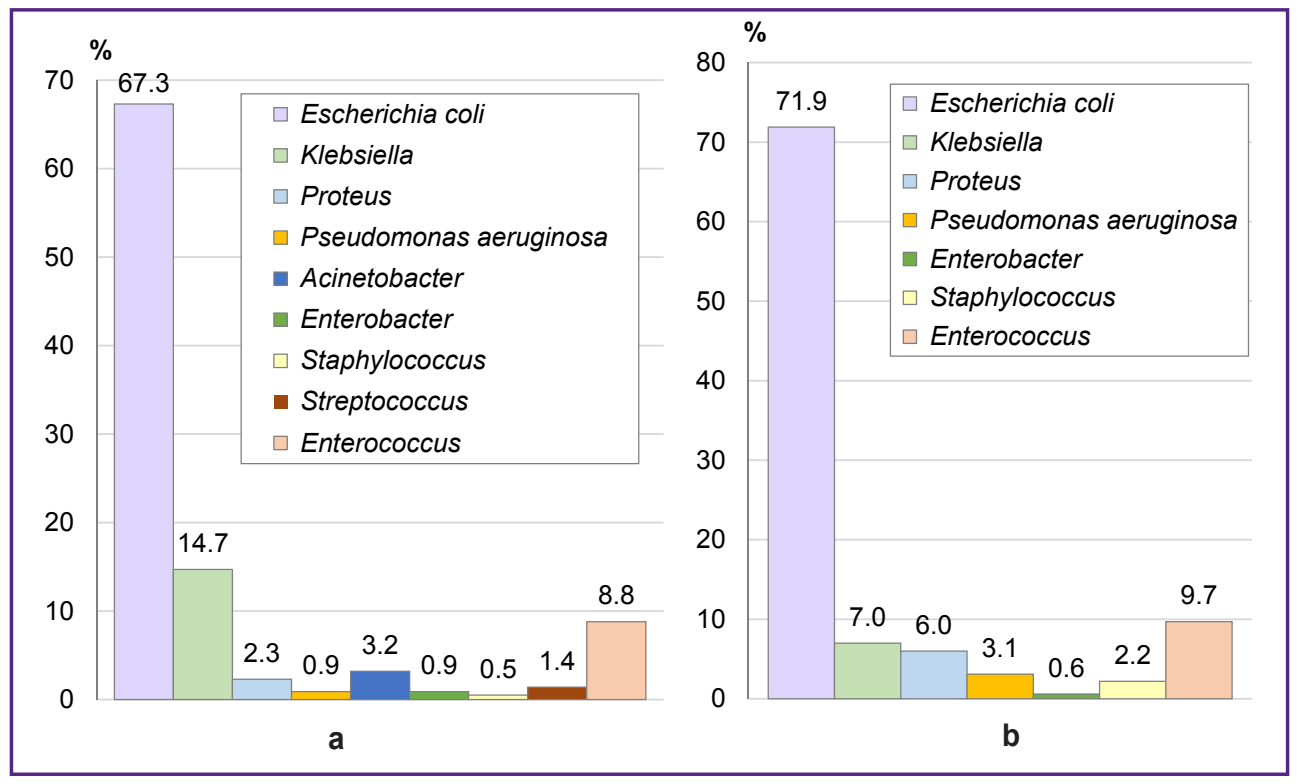

Figure 1. Spectrum of UTI pathogens in the pediatric departments:

(a) in 2014; (b) in 2016

$2 / 84$ - in the older group), and also by the Enterococcus genus $(3.8 \% ; 9 / 133$ - in the younger group; $6.6 \%$; $10 / 84$ - in the older group).

In 2016, bacterial flora was found in urine samples from 361 patients out of $865(41.7 \%)$ in both age groups. In $62.9 \%$ of cases, that was a monoculture (227/361), in $37.1 \%$ of cases (134/361) - mixed flora. In this series of samples, gram-negative bacteria also dominated (87.6\%; 199/227): E. coli $(71.9 \% ; 163 / 227)$, Klebsiella (7\%; 16/227), Proteus (6\%; 14/227) (Figure 1 (b)). Pseudomonas aeruginosa was found only in the younger age group $(p=0.067)$, which was different from the results obtained in 2014. This species accounted for $3.1 \%(6 / 195)$ of the total urine flora in this group of children. In 2016, the gram-positive bacteria were represented by Staphylococcus found only in the older children ( $3 \% ; 5 / 166 ; p=0.051)$, and Enterococcus (8.4\%; $14 / 166$ - in the older age group; $4.1 \% ; 8 / 195$ - in the younger age group).

Children with infectious and inflammatory diseases of the urinary system prevailed among the patients hospitalized in the $\mathrm{CCCH}$ (Table 2). Pyelonephritis was the most common disease among children of both age groups: acute pyelonephritis was diagnosed in $43 \%$ of them, and chronic pyelonephritis - in $13 \%$. In the younger age group, this disease was found in $71.7 \%$ of children (290/404), whereas in the older children - in $29.4 \%$ (136/461); $p=0.002$.

Children treated in the $\mathrm{CCCH}$ had significantly less congenital malformations of the urinary system as compared to the patients from the surgery department of the RCCH: less than $6 \%$ (45/865); $p=0.018$.

In patients from the $\mathrm{CCCH}$, the spectrum of pathogens in 2016 differed from that in previous years.
For example, in 2014, the presence of Klebsiella reached $14.7 \%(32 / 217)$ as compared with $1.5 \%(4 / 289)$ in 2000 and $4.6 \%(11 / 245)$ in 2013; in 2016, though, the presence of these bacteria in the urine decreased to $7 \%$ $(16 / 227)$ from $14.7 \%(32 / 217)$ in 2014 (Figure 2 (a)).

When compared with the earlier (2000 and 2003) spectra of the UTI pathogens in $\mathrm{CCCH}$ patients, the

Table 2

Diagnoses in children hospitalized in the pediatric departments of $\mathrm{CCCH}, 2016$

\begin{tabular}{lcc}
\hline \multicolumn{1}{c}{ Diagnosis } & $\begin{array}{c}\text { Incidence } \\
(\%)\end{array}$ & $\begin{array}{c}\text { Number } \\
\text { of patients (n=865) }\end{array}$ \\
\hline Acute pyelonephritis & 43.0 & 372 \\
\hline Chronic pyelonephritis & 13.0 & 112 \\
\hline Acute cystitis & 1.8 & 16 \\
\hline Chronic cystitis & 12.5 & 108 \\
\hline Acute glomerulonephritis & 2.0 & 17 \\
\hline Chronic glomerulonephritis & 2.4 & 21 \\
\hline Chronic kidney disease & 0.7 & 6 \\
\hline Dysmetabolic nephropathy & 5.0 & 43 \\
\hline Nephrotic syndrome & 3.0 & 26 \\
\hline Inherited nephritis & 1.0 & 8 \\
\hline Chronic nephritis & 2.0 & 17 \\
\hline Acute nephritis & 1.5 & 14 \\
\hline Congenital malformations \\
of the urinary organs
\end{tabular}




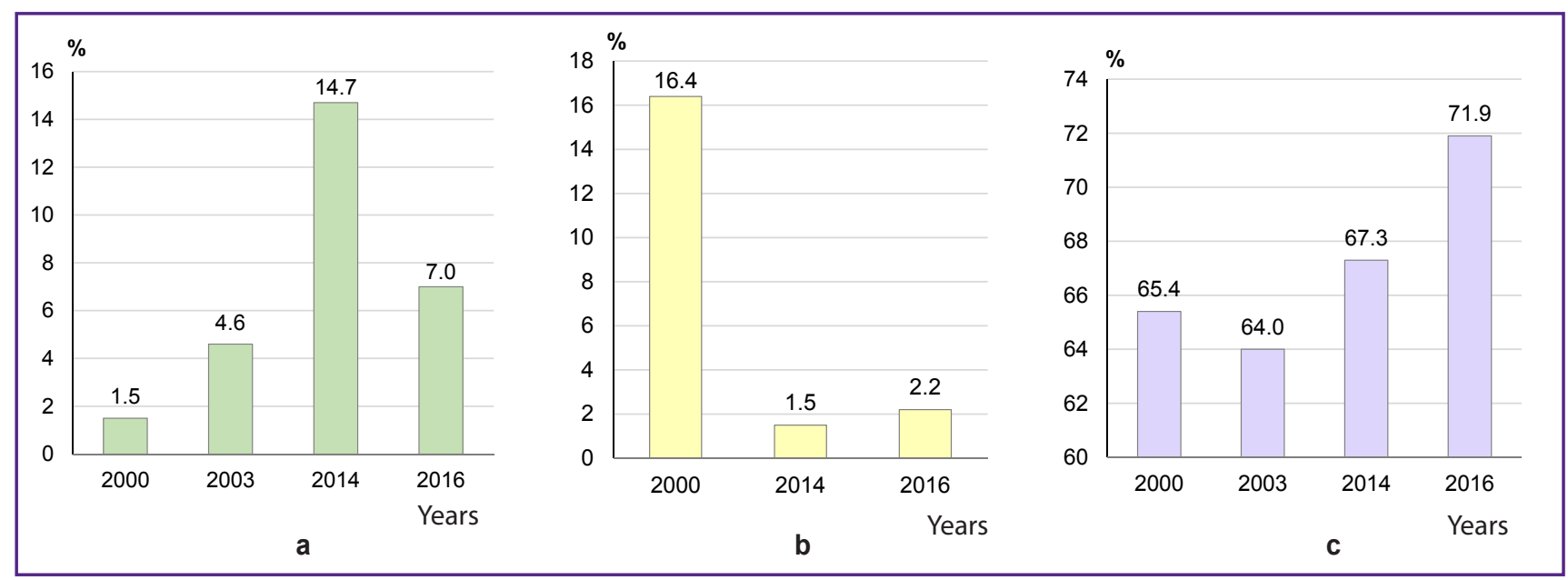

Figure 2. Prevalence of individual pathogens in the pediatric departments:

(a) Klebsiella; (b) Staphylococcus; (c) E. coli

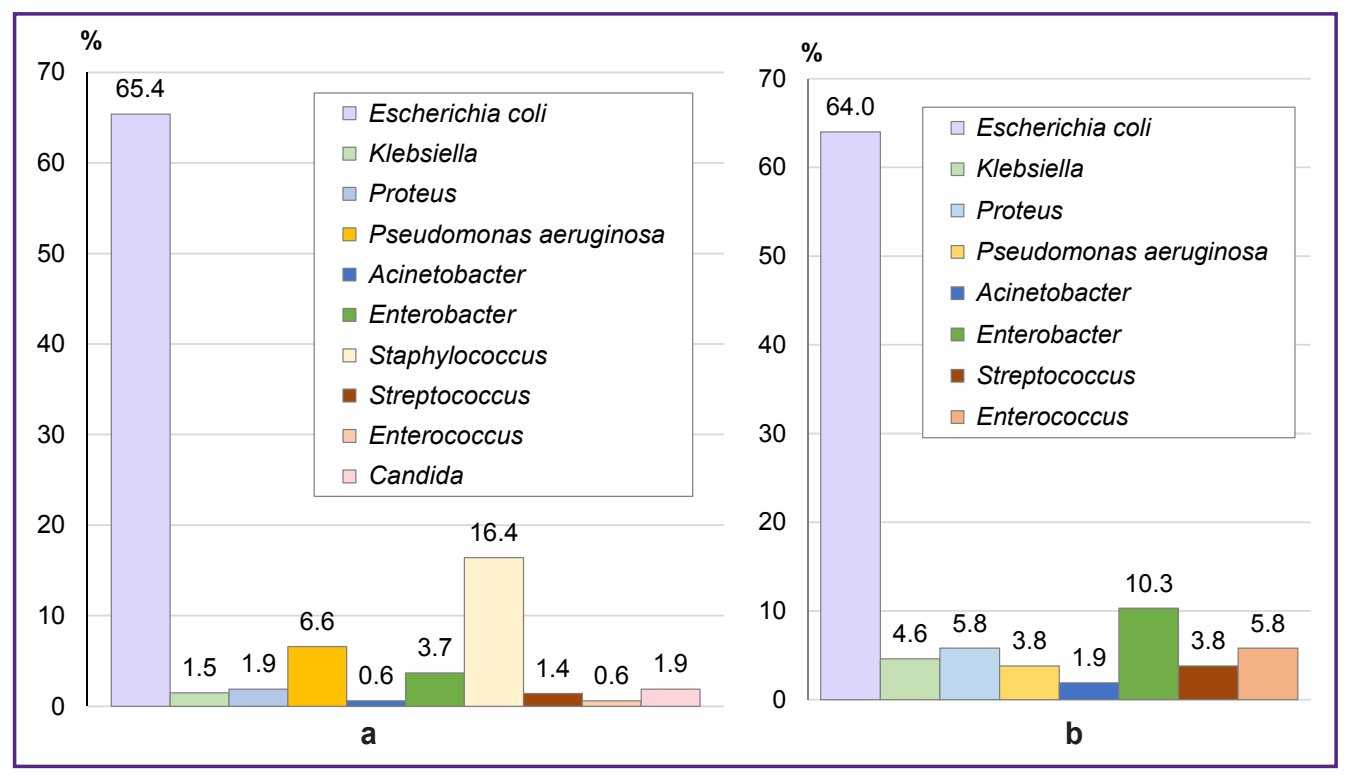

Figure 3. Spectrum of UTI pathogens in the $\mathrm{CCCH}$ :

(a) in 2000; (b) in 2003

presence of Staphylococcus has changed: in 2000 $16.4 \%(47 / 289)$, in $2014-1.5 \%(3 / 217)$, in $2016-$ $2.2 \%(5 / 227)$ (Figure 2 (b)). E. coli invariably dominated the bacterial flora of the urine: in $2000-65.4 \%$ $(189 / 289)$, in $2003-64.0 \%(157 / 245)$, in $2014-$ $67.3 \%$ (146/217), and in $2016-71.9 \%$ (163/227), thus trending to increase its presence among other urine pathogens (Figure 2 (c)).

The spectra of the UTI pathogens (according to the results from $\mathrm{CCCH}$ ) in 2000 and 2003 are presented in Figure 3.

For the period from 2005 to 2015, children with congenital malformations of the urinary organs dominated among patients of the surgery department of the $\mathrm{RCCH}$. They were diagnosed with vesicoureteral reflux (34\%; 87/254), hydronephrosis (20\%; 51/254), and bladder malformations (8.5\%; 22/254). Urolithiasis was diagnosed in $2 \%(5 / 254)$ of cases and neurogenic disorders of urination - in 5\% (13/254). In these patients, UTIs developed, in most cases, against the background of organic and functional changes in the kidneys and urinary tract.

The microbiological landscape of UTIs in obstructive uropathies and structural disorders of the kidneys and urinary tract was characterized by a wider range, lower virulence, and higher drug-resistance of the pathogenic bacteria as compared with uncomplicated infections [10].

From 2005 to 2015, urine bacterial flora was found in $43 \%(110 / 254)$ of patients hospitalized in the surgery department of the RCCH. In $43.3 \%$ of cases (48/110), 
these were bacteria monocultures, in 56.7\% (62/110) mixed flora. Comparison between the surgery and pediatric departments showed that mixed flora was more common in patients with obstructive uropathies and structural abnormalities of the kidneys and urinary tract, while bacterial monocultures were found more often in uncomplicated infections of the urinary tract. These results are well comparable with the literature [11].

In children of both age groups hospitalized either in the surgery or pediatric departments, gram-negative flora dominated: E. coli (45\%; 49/110), Klebsiella $(2.2 \% ; 3 / 110)$, and Proteus (6.5\%; 7/110) (Figure 4 (a)). However, the significance of $E$. coli for the etiology of UTIs in patients with urinary organ malformations is less than that in patients with uncomplicated UTIs. $P s$. aeruginosa was significantly more often detected in urine samples of children of the younger age $(35.4 \%$; $20 / 56)$ than that in the older group - 5.4\% (3/54) $(p=0.002)$. Ps. aeruginosa was detected mainly in patients with prolonged drainage of the urinary tract performed either with urethral catheters or pyelostomy.

The gram-positive urine flora was represented by Streptococcus found solely in the older children $(5.4 \%$; $3 / 54)$; Enterococcus were found in $5.7 \%(3 / 56)$ of the younger children and in $5.4 \%(3 / 54)$ of the older ones. However, among the gram-positive bacteria, Staphylococcus prevailed: in the younger group $16.1 \%(9 / 56)$, in the older group - $24.1 \%(13 / 54)$.

In urine cultures from children hospitalized in the surgery department of the RCCH in 2016-2017, bacterial growth was found in 147 patients out of 476 $(30.9 \%)$. These results can be explained by the fact that before their hospitalization in the surgery department, these children often receive several cycles of antibiotic therapy in a pediatric hospital. They are admitted to the surgery department in the state of remission of their chronic urinary tract diseases. Also, children with congenital malformations of the urinary tract, diagnosed antenatally before the onset of pyelonephritis, undergo surgery in the $\mathrm{RCCH}$, often in the first year of life. In bacterial monocultures isolated from the patients' urine, gram-negative flora prevailed: E. coli $(49.2 \%$; 72/147), Klebsiella (15.2\%; 22/147), Proteus (7.8\%; 11/147), Ps. aeruginosa (5.4\%; 8/147). Of the gram-positive flora, Staphylococcus was the most common genus $(7.8 \%$; 11/147) (Figure 4 (b)).

In patients from the surgery department of the $\mathrm{RCCH}$, a change in the spectrum of the urinary tract pathogens was noted. Thus in 2016-2017, Klebsiella was detected in $15.2 \%(22 / 147)$ cases whereas in 2005-2015, the respective rate was just $2.2 \%(3 / 110)$. The similar trend was also observed in the pediatric departments of the $\mathrm{CCCH}$; yet in the surgery department, the Klebsiella bacteria was detected in more patients than in the pediatric hospital $(p=0.034)$.

In the course of our study, a fairly large number of axenic urine samples were found in both the pediatric hospital and the surgery department. These results can be explained by the technical difficulties of cultivating anaerobic pathogens (non-clostridia anaerobes of various types: bacteroids, Prevotellal, actinomycetes, anaerobic cocci). Anaerobic conditions, difficult to reproduce in practice, are required to grow these bacteria.

Non-clostridia anaerobes have various factors of pathogenicity. Indirectly, they can affect the uroepithelium. Anaerobic cocci produce enzymes that may contribute to pathogenicity (urease, protease, glycosidase, etc.). For example, urease, by hydrolyzing urea to form toxic ammonia compounds, plays an important role in the genesis of UTI. Substances that make up the cell wall of gram-positive anaerobic cocci

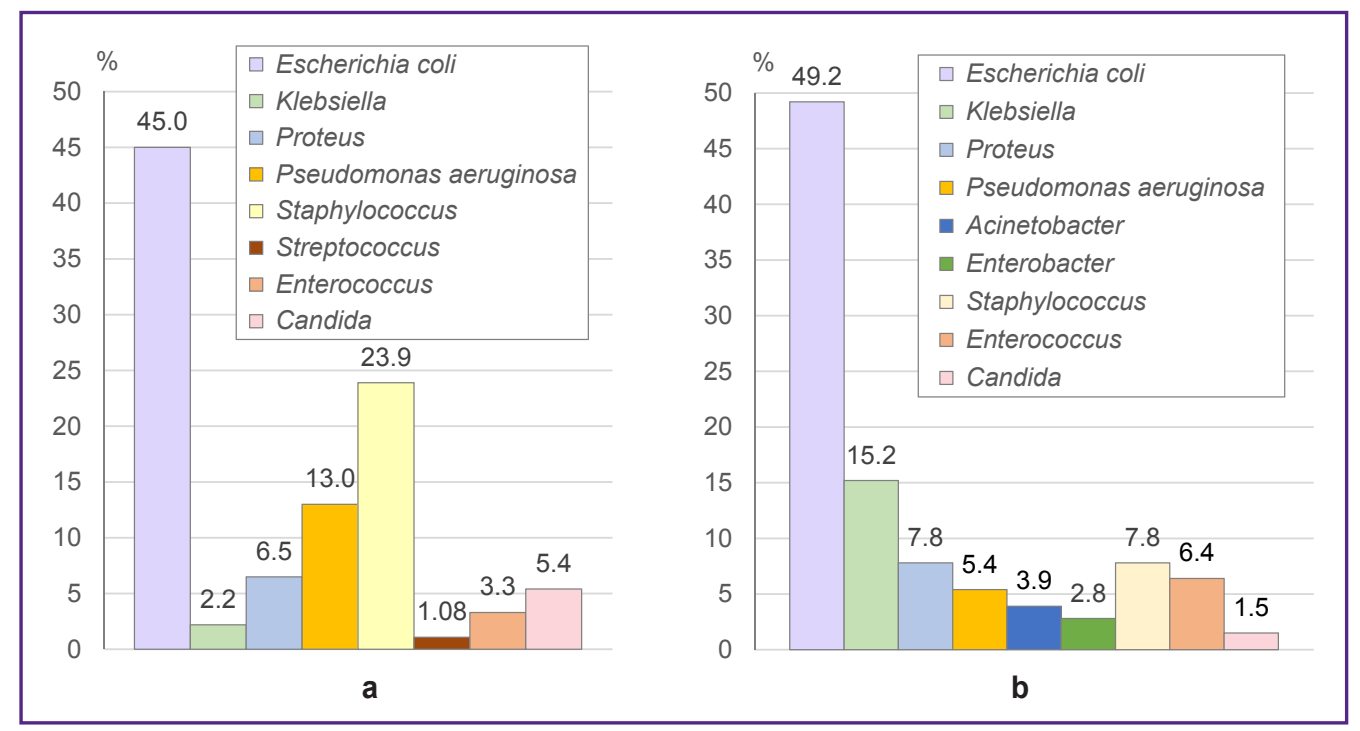

Figure 4. Spectrum of UTI pathogens in the RCCH:

(a) in 2005-2015; (b) in 2016-2017 
can act similarly to endotoxins [12]. The significant role of non-clostridia anaerobic bacteria in the development of UTIs was earlier reported [13].

Given that changes in the microbial landscape of the urine developed in parallel with the use of therapeutic antimicrobials and external disinfectants, it is necessary to carry out the timely rotation of antibacterial drugs in order to maintain the efficacy of antimicrobial therapy.

The described changes in the etiological spectrum of urinary tract pathogens support the need for close monitoring of the UTI pathogens to optimize the existing antimicrobial therapy.

\section{Conclusion}

The present study demonstrates that over the past 16 years, the spectra of UTI pathogens have changed in both pediatric and surgery departments of multidiscipline children's hospitals. Therefore, a rational choice of antibiotics and other antimicrobial agents should be based on the updated spectrum and sensitivity of these pathogens, in addition to other factors, such as the proven efficacy of the drugs, tolerability, adverse events, costs, and availability.

Monitoring the bacterial flora and assessing its drug-resistance in children with UTIs will significantly improve the efficacy of antimicrobial therapy, reduce the use of inactive antibiotics, and suppress the bacterial resistance to new antibiotics.

Research funding and conflict of interest. The study was not funded by any sources, and there are no conflicts of interest related to this study.

\section{References}

1. Ministry of Health of the Russian Federation. The Union of Pediatricians of Russia. Federal'nye klinicheskie rekomendatsii po okazaniyu meditsinskoy pomoshchi detyam $s$ infektsiey mochevyvodyashchikh putey [Federal clinical guidelines for the provision of medical care for children with urinary tract infection]. Moscow; 2015.

2. Margiyeva T.V., Komarova O.V., Vashurina T.V., Kostyushina I.S., Zrobok O.A., Sergeyeva T.V., Tsygin A.N.
Recommendations on diagnosis and treatment of urinary tract infections in children. Pediatricheskaya farmakologiya 2016; 13(1): 17-21, https://doi.org/10.15690/pf.v13i1.1509.

3. Borisov V.V. Diagnosis and therapy of urinary infections. What should always remember (clinical lecture). Part 1. Urologicheskie vedomosti 2017; 7(3): 52-59, https://doi. org/10.17816/uroved7352-59.

4. U.S. Department of Health and Human Services, Centers for Disease Control and Prevention. Antibiotic resistance threats in the United States, 2013. URL: https:// www.cdc.gov/drugresistance/pdf/ar-threats-2013-508.pdf.

5. European Association of Urology. Guidelines on Urological Infections. 2015. URL: https://uroweb.org/wpcontent/uploads/19-Urological-infections_LR2.pdf.

6. Tekhnika sbora $i$ transportirovaniya biomaterialov $v$ mikrobiologicheskie laboratorii [Technique for collecting and transporting biomaterials in microbiological laboratories]. Moscow: Federal'nyy tsentr gigieny i epidemiologii Rospotrebnadzora; 2006.

7. Ignatova M.S. Detskaya nefrologiya [Pediatric nephrology]. Moscow: OOO "Meditsinskoe informatsionnoe agentstvo"; 2011; 696 p.

8. Urologiya. Rossiyskie klinicheskie rekomendatsii [Urology. Russian clinical guidelines]. Pod red. Alyaeva Yu.G., Glybochko P.V., Pushkarya D.Yu. [Alyaev Yu.G., Glybochko P.V., Pushkar' D.Yu. (editors)]. Moscow: GEOTARMedia; 2016; 496 p.

9. Kozlov S.N., Kozlov R.S. Sovremennaya antimikrobnaya khimioterapiya [Modern antimicrobial chemotherapy]. Moscow: OOO "Meditsinskoe informatsionnoe agentstvo"; 2017; 400 p.

10. Yakovets Ya.V., Neymark A.I. Rational antibiotic treatment of non-specific inflammatory diseases of the urogenital tract. Meditsinskoe obozrenie. Nauka i praktika 2015; 3(3): 4-8.

11. Lyamin A.V., Botkin E.A., Zhestkov A.V. Medical problems associated with bacterial biofilms. Klinicheskaya mikrobiologiya i antimikrobnaya khimioterapiya 2002; 4: 268275.

12. Naboka Y.L., Kogan M.I., Gudima I.A., Chernitskaya M.L., Miroshnichenko E.A., Vasilieva L.I. Urine bacterial spectrum and persistence factors of microorganisms, isolated in women with lower urinary tract infection. Byulleten' Orenburgskogo nauchnogo tsentra UrO RAN 2012; 2: 5.

13. Lartsova E.V., Spivak L.G., Morozova O.A. Bacterial contamination of urine in patients with large and staghorn kidney stones. Vestnik urologii 2015; 2: 34-40. 